\title{
Article \\ Optimal Sizing of Fuel Cell Hybrid Power Sources with Reliability Consideration
}

\author{
Adriano Ceschia ${ }^{1,2}$, Toufik Azib ${ }^{1, *(1)}$, Olivier Bethoux ${ }^{2}$ and Francisco Alves ${ }^{2}$ \\ 1 ESTACA'LAB, S2ET Department, École Supérieure des Techniques Aéronautiques et de Construction \\ Automobile (ESTACA)—Paris Sacley, 12 Avenue Paul Delouvrier, 78180 Montigny-le-Bretonneux, France; \\ adriano.ceschia@estaca.fr \\ 2 GeePs, Group of Electrical Engineering-Paris, UMR CNRS 8507, CentraleSupélec, Univ. Paris-Sud, Univ. \\ Paris-Saclay, Sorbonne Université, 3 rue Joliot-Curie, 91192 Gif-sur-Yvette, France; \\ olivier.bethoux@geeps.centralesupelec.fr (O.B.); francisco.alves@geeps.centralesupelec.fr (F.A.) \\ * Correspondence: toufik.azib@estaca.fr; Tel.: +331-76-52-11-03
}

Received: 9 June 2020; Accepted: 6 July 2020; Published: 7 July 2020

check for updates

\begin{abstract}
This paper addresses the issue of optimal sizing reliability applied to a fuel cell/battery hybrid system. This specific problem raises the global problem of strong coupling between hardware and control parameters. To tackle this matter, the proposed methodology uses nested optimization loops. Furthermore, to increase the optimal design relevance, a reliability assessment of the optimal sizing set is introduced. This new paradigm enables showing the early impact of the reliability criteria on design choices regarding energetic performance index. It leads to a smart design methodology permitting to avoid complexity and save computing time. It considerably helps design engineers set up the best hybridization rate and enables practicing tradeoffs, including reliability aspects in the early design stages.
\end{abstract}

Keywords: optimal sizing; reliability assessment; design methodology; hybrid power source; fuel cell/battery

\section{Introduction}

The automotive industry is perpetually setting their focus on the development of alternative energy sources to reduce oil dependence, greenhouse gas emissions and noise pollution. In this context, powertrain electrification provides the most promising solution and allows the transition to new mobility services. In most cases, it uses more than one power source in order to improve the vehicle efficiency and reliability. Several hybrid architectures are under development to power the electric powertrain. The hybrid electric vehicle (HEV) uses different storage solutions and different energy sources, mainly fuel cells, batteries, flywheels and ultracapacitors [1-3]. The storage device is the key of a successful powertrain electrification since it enhances the system capability with both high power and high energy densities.

Hybridization unfortunately increases the complexity of the drivetrain, involving further multiphysics and multidisciplinary problems with additional parameters and constraints, strong interaction and interdependence between the system constituents, new driving modes, etc. In order to deal with the full complexity of the system, many performance indices must be integrated [3-6]. The project designer has to consider the most suitable components, their optimal size, and the related energy management strategy. It is, therefore, an industrial challenge to optimize the design of such a system.

In this context, developing a suitable engineering methodology has received a significant amount of attention. In the literature, the numerous works dedicated to achieve an efficient HEV design can be 
subdivided into two categories: empirical approaches and computational approaches [6]. The former are mainly based on experience feedback using the designer's expertise. They also include reasoning and direct analytic processes forming a sequence of design steps. These approaches have proved their effectiveness and performances for simple and conventional cases. However, facing a complexity increase requires using computational techniques. They use algorithmic processes mainly based on optimization routines. The standard approach provides a limited and restricted solution around an operating point of the typical range of the system; the rated one is commonly used. In order to improve its performance, several works have considered a wide range of operating points $[7,8]$. They generally use a systematic approach either based on a sequential process based on several individual optimizations or relying a multi-objective optimization [9-14]. Their performances are impacted by the trade-off between formulation complexity, computational time and exploration capabilities.

A set of new approaches are emerging [15-18] based on combined and mixed methods concepts to address the increasing complexity of the system, by considering the major parameters affecting the system performances. They can be classified in three categories: iterative, simultaneous and nested (bi-level) approaches. Regarding interaction between sizing and control designs, several works have demonstrated the relevance and performance of simultaneous and nested approaches $[19,20]$.

Simultaneous approaches optimize both the sizing and control variables in the same optimization formulation, which gives rise to complex analytical structures and presents a challenge to practical resolution (formulation, computation time, type of problems). Conversely, nested ones maintain decomposition principles using dynamic coupling to ensure system optimality. They enable quick, practical and simple implementation. Moreover, a new nested methodology for complex system design has been suggested, able to tackle large search spaces [17]. It simultaneously tunes and designs the energy management and component sizing by optimizing the main powertrain parameters in conformity with the specifications. Technically, it uses two nested loops, combining the particle swarm optimization (PSO) technique's performance [21,22] and the rapid Pontryagin optimal control algorithm (PMP Pontryagin's Minimum Principle) [23-25]. The former permits addressing vast search spaces for design component parameters while the latter enables considering energy management behaviour. This strategy achieves faster convergence to the global optimal design solution and provides a good accuracy and robustness.

For electrical vehicle (EV) applications, the reliability is a key constraint. Most of design processes integrate reliability assessments in the post-design phase, i.e., during the control scheme's synthesis [3,26-28]. At this late step, it becomes difficult to eliminate all risk of unfeasibility. Practical remedies to this issue include either the development of optimal control together with degraded modes monitoring [27-31] or the use of an oversized system. None of these solutions provides a really efficient solution and ensures the system reliability in real-time operating conditions. In recent works [27,28], degraded modes of the power management system have been introduced to optimize fuel cell/battery hybrid system availability and reliability. These studies have shown that the battery degradation and its lifetime reduction highly depends on the considered sizing. Consequently, to increase the optimal design relevance and match to industrial challenges, a reliability assessment process has to be introduced at the same level as the design approach. This new paradigm enables showing the early impact of the reliability criteria on design choices regarding energetic performance index.

To put this notion to the test, the present work considers a fuel cell hybrid vehicle (FCHV) which is one of the attractive HEV architectures. It combines the most appropriate technologies for vehicles nowadays, a hydrogen fuel cell PEMFC (proton exchange membrane fuel cell) with a Li-ion battery. The fuel cell is controlled to ensure the required energy supply, whereas the transient power requirement and braking energy are provided by the battery. Subsequently, the battery operates under harsh and severe conditions and its durability has to be closely considered [1,3]. Hence, a battery reliability assessment is considered. The battery is modelled according to Wöhler damage representation. The battery state of health $(\mathrm{SOH})$ is represented by a linear trend extrapolation which can be easily integrated into the optimization approach and respect computation time constraints. It constitutes a 
major advance compared with the current standard approaches which commonly introduce reliability constraints once the whole system is designed [32,33]. The latter leads to complex implementations based on extensive tests and, thus, expensive and time-consuming processes. Conversely, the suggested approach is based on a linear trend extrapolation of battery $\mathrm{SOH}$ enabling to study in the early steps of design how the reliability aspect may impact the hybrid power system sizing. Additionally, the present study also aims at finding new recommendations regarding the cost functions and the constraints of the design optimization approach.

The rest of this paper is organized as follows. Section 2 presents the proposed optimal design approach, the studied use case (fuel cell/battery hybrid system) and its related requirements. Section 3 introduces the extrapolation of lifetime modelling of the system under study and the proposed battery reliability assessment. This is followed by a detailed description of the reliability process integration in the next section. Section 5 gives the simulation results and discussion. Finally, the last section provides the conclusion and perspectives.

\section{Optimization Sizing Approach}

\subsection{Principle of Sizing Approach}

The optimal design aims at setting the value of the key parameters influencing system design based on one or more performance indices. Considering the interdependence between sizing and control parameters, the combined methodology is appropriate. The proposed approach is built on nested optimizations as presented in Figure 1. This global methodology is detailed in [17].

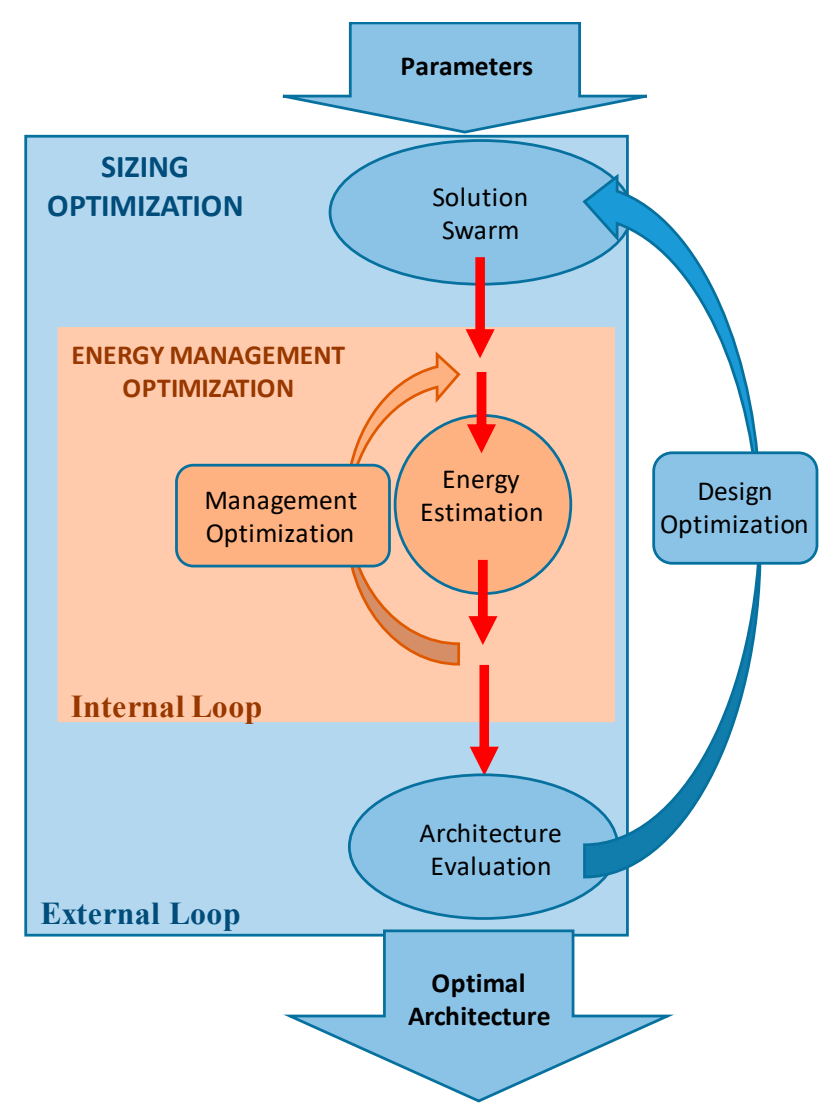

Figure 1. Overview of the suggested design optimization.

It relies on a two-level optimization scheme; the external loop permits to optimize the architecture sizing which means that it enables to define the optimal powertrain parameters with respect to the 
hybrid architecture specifications. PSO technique use permits to address large design space while leading to a simple and time-saving calculation implementation [21,22].

The control tuning parameters is considered; by introducing an energy consumption criterion in the internal loop (Figure 1), enabling to optimize the consumption of the designed architecture according to the total driving cycle. For this issue, the PMP based optimal control is introduced with the ability to compute and optimize a single trajectory of the cost function called the Hamilton function. This leads to reduced computational time and accelerates the convergence, even for large design space exploration, which is a key figure for the proposed approach [23-25].

Unlike conventional methodologies, the new proposed paradigm allows to maximize the space design exploration for more potential design candidates, and offering the best trade-off between computing time and optimal design.

In summary, the proposed approach uses two nested optimization loops: the external one searches the main optimal parameters of the architecture sizing according to the specifications (constraints and criteria) defined by the expert user, while the internal loop makes the external criterion using the energy management optimization. This internal loop evaluates the energetic performance of each tested architecture sizing, which provides the cost function of the external loop. Figure 2 illustrates the workflow involved for the proposed design approach.

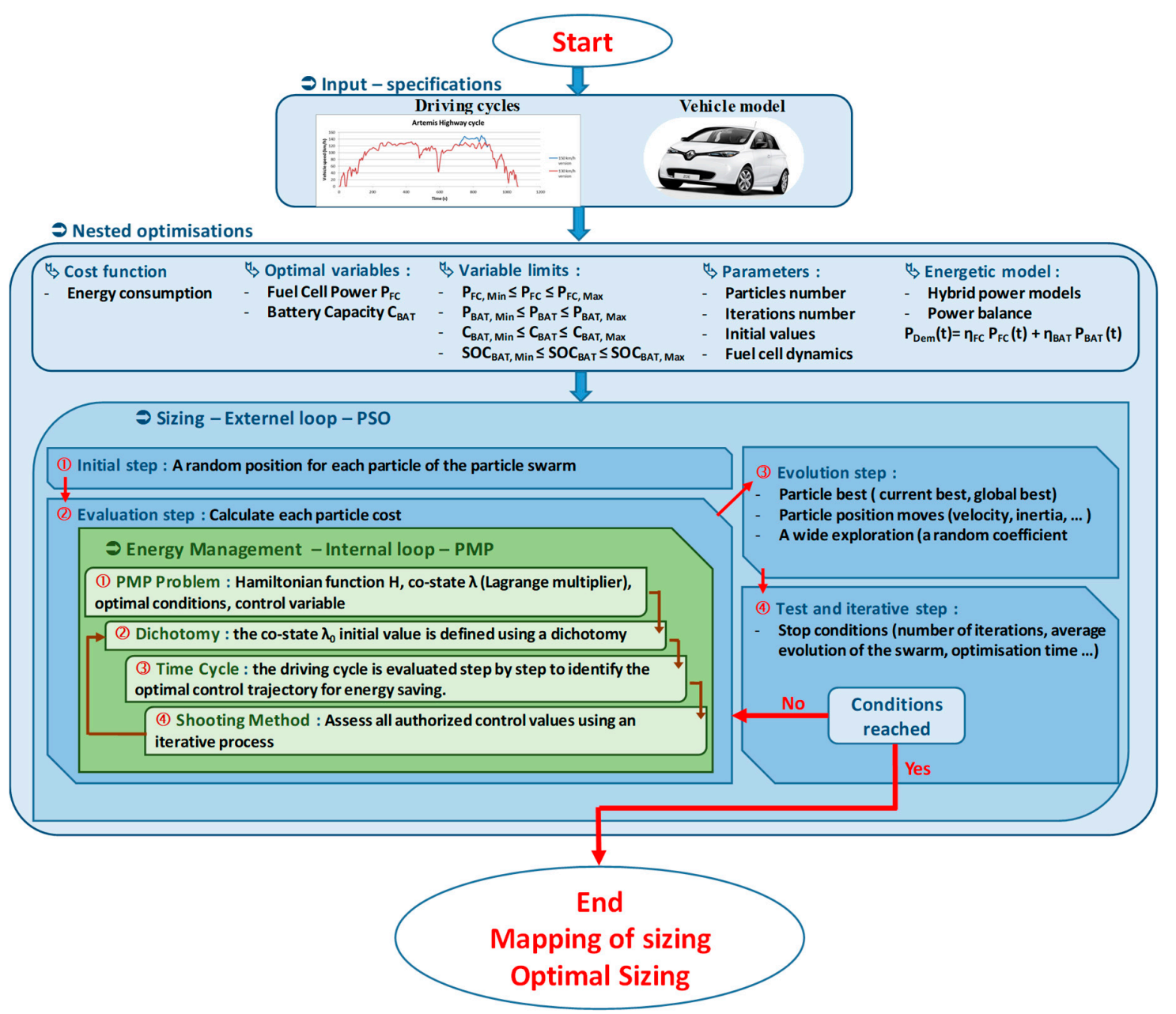

Figure 2. Workflow implementing the proposed nested optimization approach.

\subsection{Use Case}

The selected system is a parallel hybrid fuel cell/battery source including a DC/DC converter for each source. It offers a high freedom degrees that is relevant and suited for optimal design (sizing and 
energy management) [34]. Figure 3 illustrates the functional diagram of this architecture, with the fuel cell as the main energy source and the battery as the auxiliary power source. The vehicle specifications considered are related to a city car, similar to a Renault Zoe.

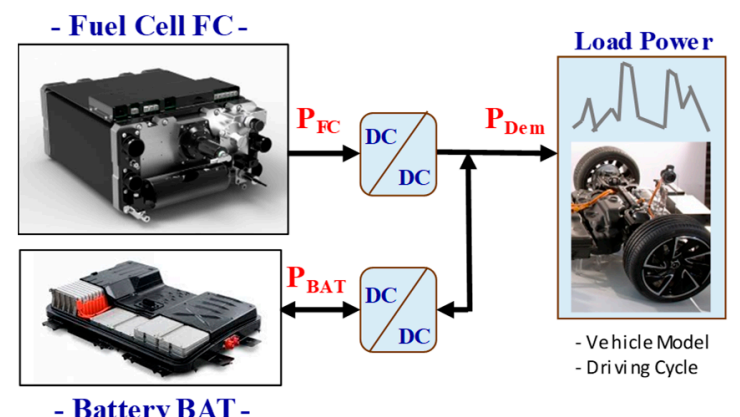

Figure 3. Parallel hybrid power source architecture.

The FCEV demand power is computed according to the longitudinal dynamics equation of the vehicle considering the vehicle speed $V$ and forces due to vehicle acceleration, drag and friction, and road slope, as follows:

$$
P_{\text {Dem }}(t)=C_{r} M g \cos (\alpha) V(t)+M g \sin (\alpha) V(t)+M \frac{d V}{d t} V(t)+\frac{1}{2} \rho S C_{x} V^{3}(t)
$$

where $P_{\text {Dem }}$ is power demand, $C_{r}$ and $C_{x}$ are the friction and aerodynamic coefficients, respectively, $\rho$ is the air density, $S$ is the front surface area, $M$ is vehicle mass, $g$ is gravity acceleration and $\alpha$ is slope of the road.

In order to consider the randomness feature of real driving cycle (stochastic characteristic), different road conditions are discussed including WLTC, US Highway and US 06.

\section{System Reliability Approach}

This study concerns the reliability assessment of fuel cell/battery hybrid power source. This powertrain configuration aims at letting the fuel cell provide the main energy autonomy and the battery provide transient power demand. The focus is made on battery storage device, which is mainly impacted by durability concerns in a typical automotive application [26]. It is considered that the fuel cell, whose performance depends mainly on membrane behaviour (gas pressure and velocity, thermal and water management, etc.) is well managed and operates under low dynamics conditions, which is a positive factor for its lifetime [35]. Battery degradation leads to capacity loss and internal resistance increase, which limit the energy availability and the power capability, respectively. State of health $(\mathrm{SOH})$ reflects the battery degradation along its lifetime. This indicator enables to obtain an appropriate reliability impact figure which can be integrated into the optimization approach. The $S O H$ equation is defined in Equation (2):

$$
S O H=\frac{C_{B A T, C}}{C_{B A T, \text { Init }}}
$$

where $S O H$ is BAT state of health, $C_{B A T, C}$ and $C_{B A T \text {,Init }}$ are the current and initial battery capacities, respectively.

Lithium-ion battery performances decline with use and time. Their lifetime degradation is a complex process and subject to different factors and mechanisms (electrical, thermal, humidity, mechanical and chemical parameters). Among these, the thermal aspect mainly drives the aging effects [36-41]. Technically, various studies have shown that the main effects on battery expected lifetime are: the calendar aging effect and the cycling effect [41,42].

First, the calendar aging effect $[36,37]$ mainly depends of the storage conditions as the ambient temperature and the battery state of charge (SOC). The SOC equation is defined in (3): 


$$
S O C=S O C_{0}+\frac{\eta_{B A T}}{C_{B A T}} \int i_{B A T} d t
$$

where $S O C$ and $S O C_{0}$ are, respectively, the current and initial state of charge. $\eta_{B A T}, C_{B A T}$ and $i_{B A T}$ are battery efficiency, capacity and current, respectively.

Second, the cycling aging is related to several elements depending on battery usage $[38,39,43]$ and energy management optimization (power sharing). The main stress factors are the number of cycles, the depth of discharge $(D O D)$, the battery temperature and the average demanded power.

Considering different studies in literature [38-43], usually battery aging and $\mathrm{SOH}$ are evaluated according to calendar and cycling extensive tests to establish physical modelling or empirical modelling. For example, in $[4,44]$, the degradation factors of the Li-ion battery are estimated using a semi-empirical model according to the manufacturer's data, by considering the instantaneous capacity loss evolution as a function of rated current. To model the battery degradation mechanism, Leng et al. [45] and Zou et al. [46] propose an analytical and electrical models, respectively. They both consider the influence of the operating temperature on the batteries lifetime for HEVs. Zou et al. [46] and Ecker et al. [47] performed a set of experiments to estimate the key aging factors affecting batteries lifetime.

These different solutions are complex and require specific experiment tests, leading to an expensive and time-consuming process. Moreover, they do not adequately take into account stochastic automotive driving cycle. Accordingly they are not suitable for a good design approach.

The major test data provided by studies in $[38,39,46,47]$ were obtained using the following procedures:

- For the DOD study the cycle was a CCCV (constant current constant voltage) charge at $1 C$, followed by a $30 \mathrm{~min}$ break and then a CC (constant current) discharge to the desired DOD at $1 \mathrm{C}$ and, finally, a $5 \mathrm{~min}$ break. The details of this procedure is presented in [38,39].

- For the C-rate study, the cycle was a $100 \%$ DOD performed at a different C-rate in a continuous fashion. For more details, see [38,39].

Against this background, both calendar and cycling test data provided by studies in $[38,39,46,47]$ are analysed to establish mathematical relationships between the monitored parameters influencing battery aging, such as temperature, $S O C$ and rated current. It allows an extrapolation for reliability assessment. First, the $\mathrm{SOH}$ evolution could be modelled using the number of cycles and the related electrical operating conditions. It reveals to be a relevant metric to assess the ageing rate of a lithium-ion battery (Figures 4 and 5). It uses the concept of the Wohler curve describing the relation between stress level and the number of cycles to failure. This criteria has initially been introduced for mechanical fatigue concerns and later widely adopted in varied fields of application. This makes possible the estimation of the residual lifetime ( $\mathrm{SOH}$ change) by identifying the remaining number of cycles.

For EV application, the end-of-life $(E O L)$ of a battery is related to capacity performance and can be determined until loss of battery capacity reaches $20 \%$ which leads to a certain number of cycles $[4,48,49]$. The experimental data demonstrates that the $\mathrm{SOH}$ stays relatively stable and exhibits a quasi-linear behaviour for different operating condition until EOL is reached (Figures 4 and 5). Thus, there is obviously a proportional relationship between the number of cycles and $D O D$ level as well as the rated current, with the same trend as illustrated in Figures 6 and 7. The SOH model is thus expressed through the following equations and remains valid until EOL; Equation (4) is defined for a given rated current and Equation (5) is defined for a given DOD obtained from the experimental process.

$$
\begin{aligned}
& \left\{\begin{array}{c}
S O H_{D O D}(\%)=100-\frac{D O D(\%)}{\gamma} \cdot N_{C y c l e, D O D} \\
N_{C y c l e, D O D}=\alpha \cdot D O D(\%)+\beta
\end{array}\right. \\
& \left\{\begin{array}{c}
S O H_{I c}(\%)=100-\frac{C_{\text {rate }}}{\delta} \cdot N_{C y c l e, I c} \\
N_{C y c l e, I c}=\rho \cdot C_{\text {rate }}+\sigma
\end{array}\right.
\end{aligned}
$$


where $S O H_{D O D}$ and $S O H_{I c}$ are state of health as a function of $D O D$ and rated current, respectively. $N_{C y c l e}$, $D O D$ and $N_{C y c l, I c}$ are number of cycles according to a DOD level and a ratted current, respectively. $C_{\text {rate }}$ is charging/discharge current. $\alpha, \beta, \gamma, \delta, \rho$ and $\sigma$ are fitting parameters.

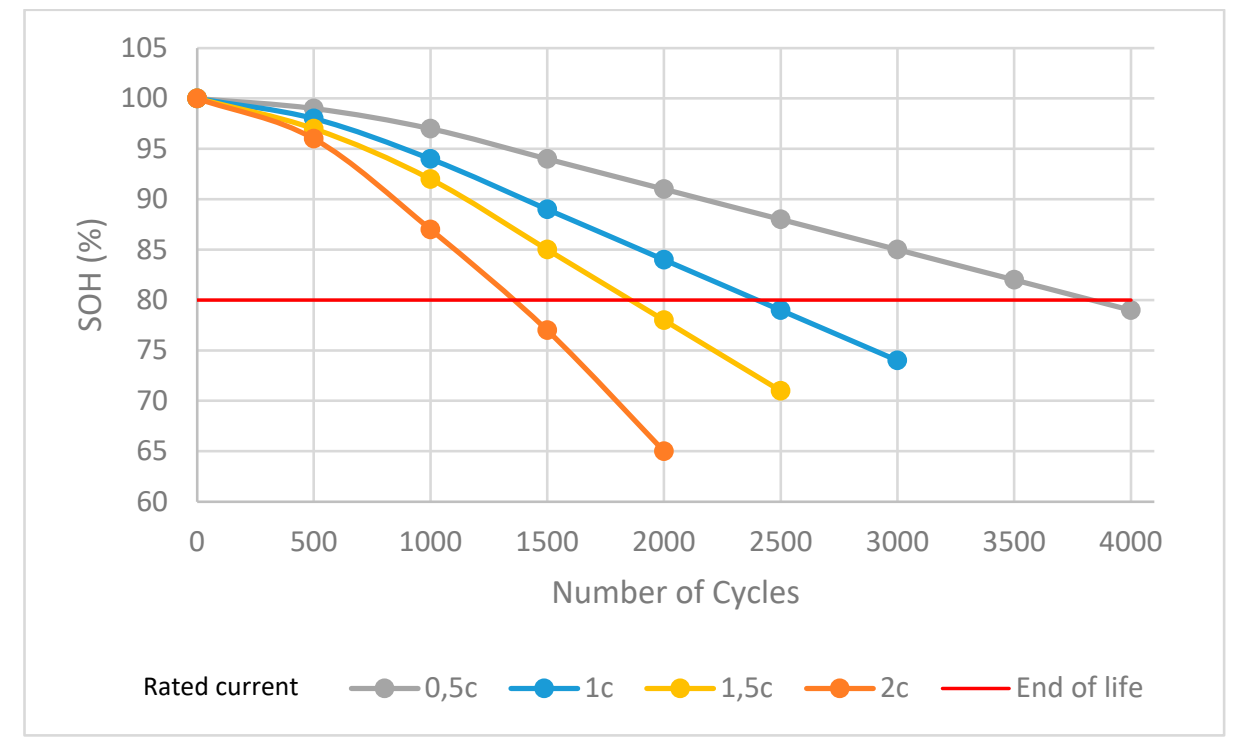

Figure 4. Battery lifetime data at various rated current.

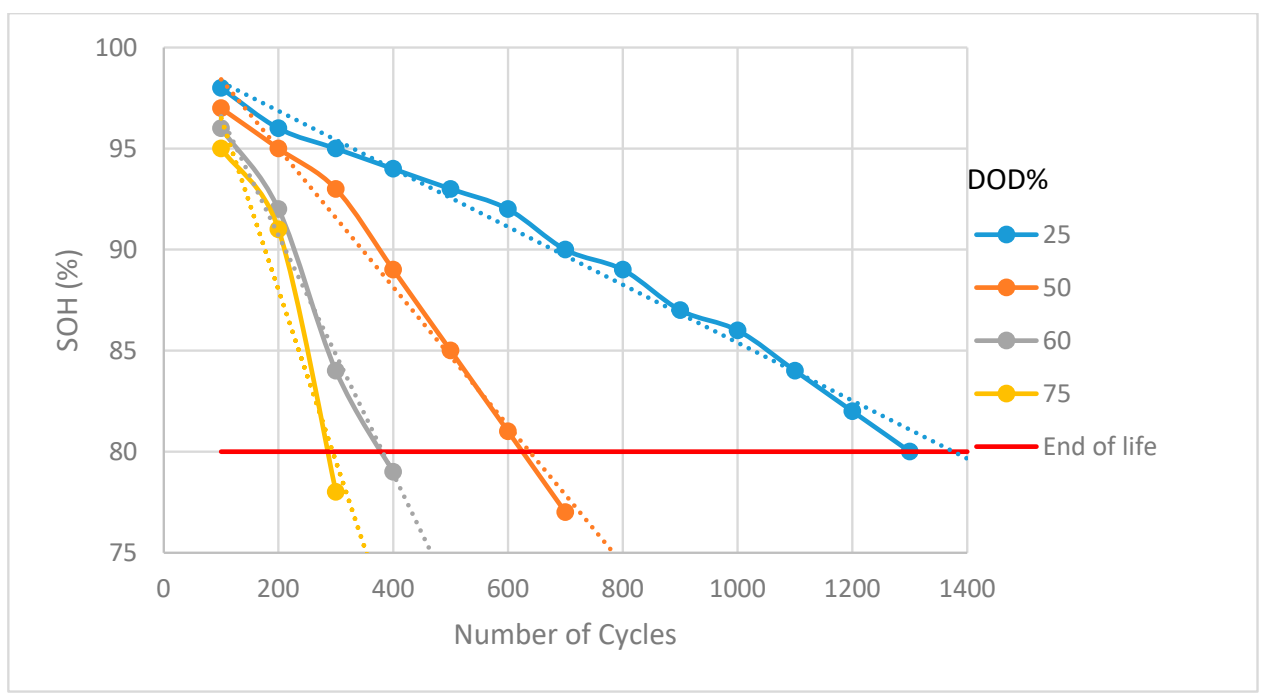

Figure 5. Battery lifetime data at various $D O D$.

The study is carried with full range variation of the SOC from $20 \%$ to $90 \%$, which leads to a DOD of $70 \%$.

It is important to extend this degradation model developed under specific experimental operating conditions to real-life driving conditions. For this purpose, a similar principle is applied to describe the $\mathrm{SOH}$. It assumes that the variation of the stress factors follows its average values until EOL is reached. In this framework, the idea is to link the battery's entire lifetime to the energy exchanged by the battery until EOL. To cover up the dynamic of the operating conditions, the exchanged energy is weighted by a degradation degree coefficient. This is later deduced from the $\mathrm{SOH}$ test dataset.

In sum, the reliability assessment is obtained by estimating the residual lifetime, depicted by the weighted of cumulative energy exchanged according to the power density of cycle. Figure 8 shows the different steps of the proposed reliability assessment approach. 


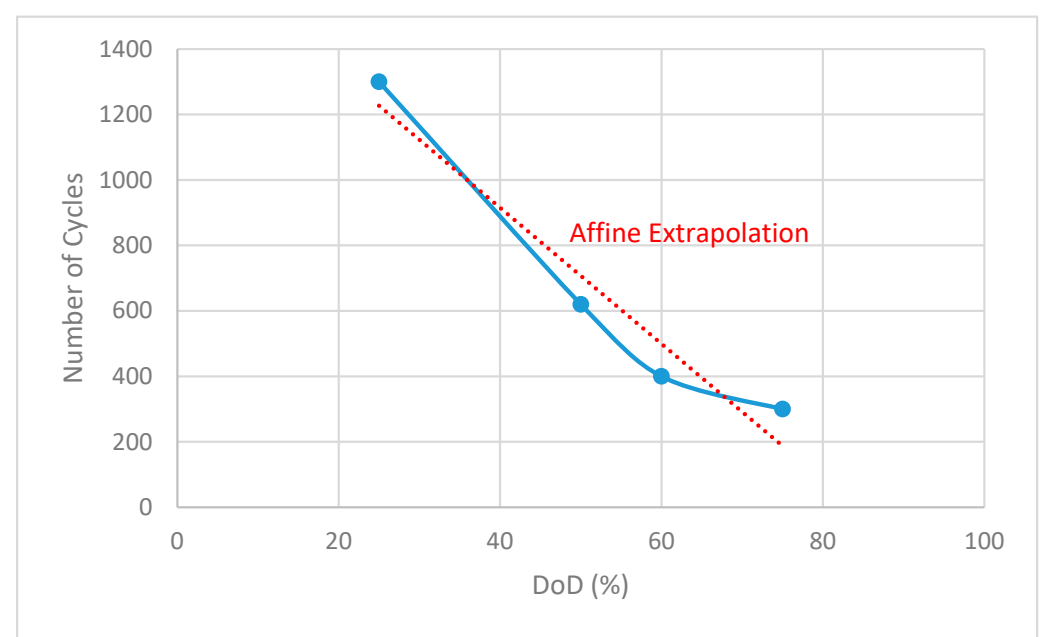

Figure 6. A linear trend extrapolation of $\mathrm{SOH}$ according to $\mathrm{DOD}$ variation.

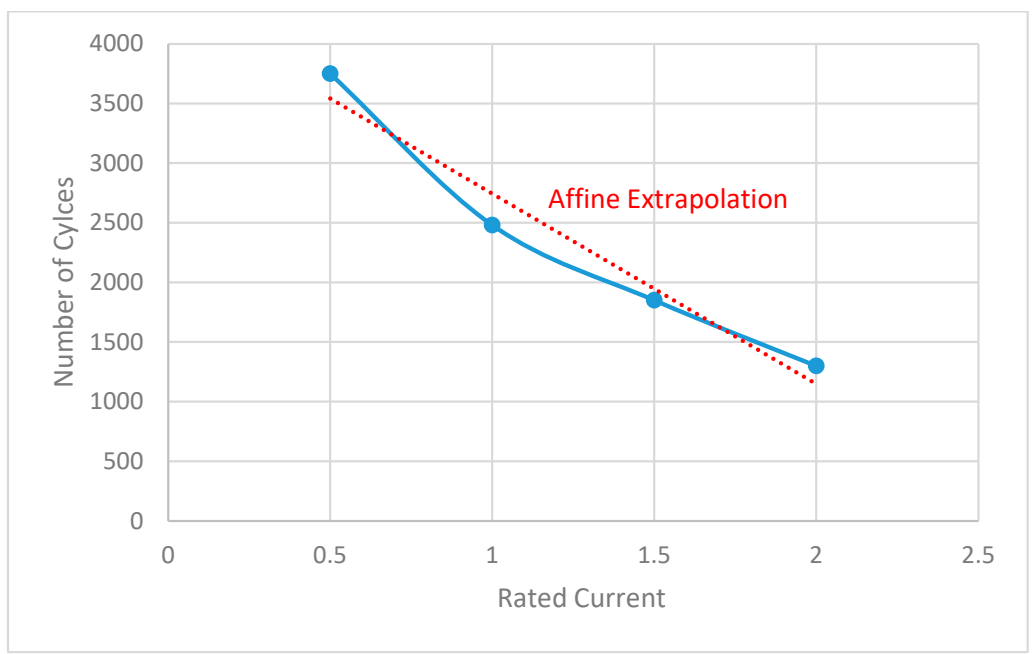

Figure 7. A linear trend extrapolation of $\mathrm{SOH}$ according to rated current variation.

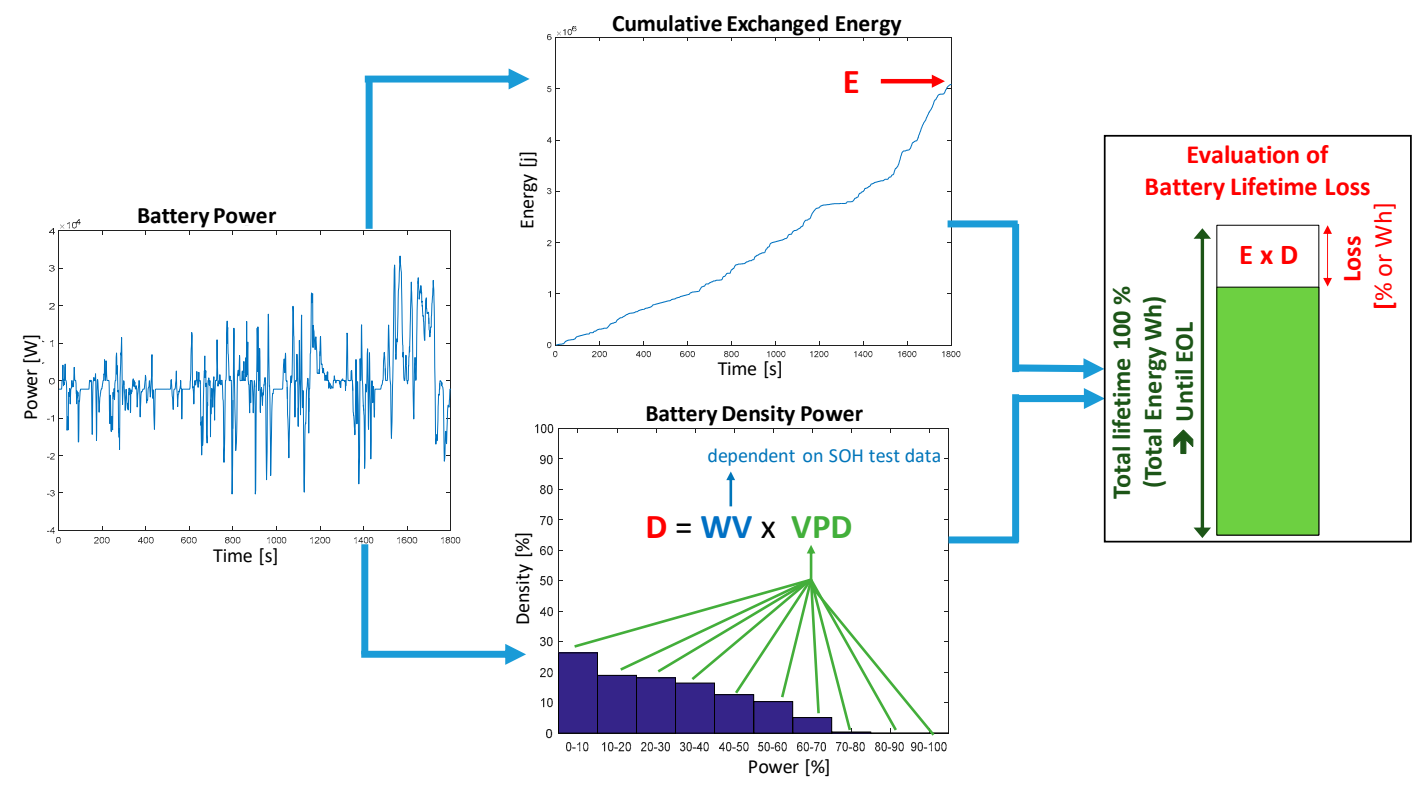

Figure 8. Reliability assessment approach. 
First, the total exchange energy is cumulated by simple counting for the considered driving cycle (WLTC) and calculated by:

$$
\left\{\begin{array}{l}
E_{B A T}(J)=\sum\left|P_{B A T}(W) \cdot T_{S}(s)\right| \\
E_{B A T, T o t, \text { Init }}(J)=E_{B A T} \cdot N_{C y c l e, \text { Init }}
\end{array}\right.
$$

where $E_{B A T}$ and $P_{B A T}$ are battery cumulated energy and power, respectively. $E_{B A T, \text {,Tot,Init }}$ and $N_{C y c l e, \text { Init }}$ are total initial battery energy and number of cycle, respectively. $T_{S}$ is sample time.

Then, a power density histogram is introduced and can be set according to various power levels (from $10 \%$ to $100 \%$ in increments of $10 \%$ ). This is accomplished by counting the energy exchanged for each power level normalized to the available energy of cycle.

$$
V P D_{i=1 \ldots 10}=\frac{\left(\sum P_{B A T, i} \times T_{S}\right)}{E_{B A T}} \cdot 100
$$

This enables to identify a vector of power distribution $(V P D)$ for a specific driving cycle, the WLTC one is given by:

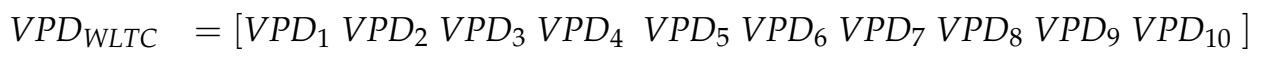

$$
\begin{aligned}
& =[25 \% 18 \% 17 \% 15 \% 11 \% 9 \% 4 \% 1 \% 00 \text { 0 } 0 \text { ] }
\end{aligned}
$$

Finally, each power distribution level is weighted as a result of the variation of dynamic operating conditions (power level/rated current) according to the lifetime experimental data. For this use case, a linear regression is considered, which can be customized depending on the results data (for example non-linear trend). A weighting vector $(W V)$ is thus achieved and expressed as:

$$
W V=\left[\frac{1}{3} \frac{2}{3} \frac{3}{3} \frac{4}{3} \frac{5}{3} \frac{6}{3} \frac{7}{3} \frac{8}{3} \frac{9}{3} \frac{10}{3}\right]
$$

Finally, there remains to assess the degradation degree coefficient related to the total exchange energy. It symbolizes the degradation degree $(D)$ of the battery calculated as follows:

$$
D=\operatorname{Mean}(W V \cdot V P D)
$$

Total battery degradation is expressed as a percentage value for lifetime loss $\left(L_{\text {Loss }}\right)$ or consumed energy. This procedure is repeated until depletion, which means EOL conditions, through the following equation:

$$
L_{\text {Loss }}(\%)=\frac{E_{B A T} \cdot D \cdot 100}{E_{B A T, T o t, I n i t}}
$$

The approach's flexibility enables direct adaptation to different battery technologies by updating their lifetime data. It produces very fast results with sufficient accuracy suitable for the optimisation sizing approach. The following section considers reliability process integration to analyse its impact on the hybrid power system sizing based on an energy performance index.

\section{Reliability Process Integration}

A reliability process integration is introduced to assess the reliability impact on the sizing of the hybrid power system under the energy performance index. This process supports the proposed reliability assessment approach and a reliability assessment of the set of solutions.

Figure 9 represents the reliability process integration using the following steps:

- Design optimization step: the proposed combined design approach gives a consistent set of solutions whatever the driving cycle. The mapping of designed solutions is depicted by a bowl shape surface. It shows clearly a trade-off between component sizing and energy saving. The hybrid system design is mainly affected by the load average power and the load power dynamics. 
- Reliability assessment step: For each driving cycle, the set of design solutions is assessed for reliability using lifetime loss rate. To this end, the linear trend extrapolation of battery $\mathrm{SOH}$ is considered, as explained before.

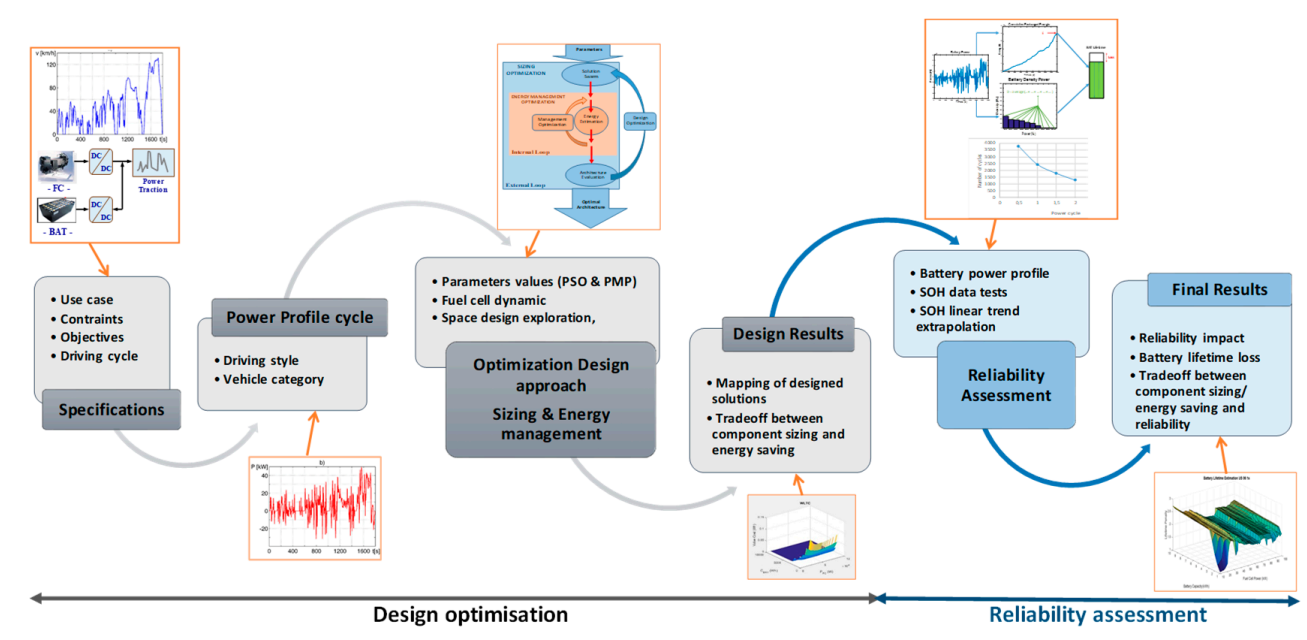

Figure 9. Reliability process integration.

To improve design results, different FC dynamics have been introduced. It helps considerably design engineers to set up the best hybridization rate and enables them to practice trade-offs, including reliability aspects, in the early steps of the design.

\section{Results and Analysis}

The proposed process is evaluated by extensive simulation using MATLAB/SIMULINK environment (R2018a, MathWorks, Natick MA, USA). A map of different sets of solutions, for different driving cycles (WLTC, US 06 and US Highway), and with various FC dynamics (1 s, 5 s and 10 s: time required to achieve the rated power).

During the first step, the design optimization results show that the FC sizing is closely linked to the load power average (energy source) while its battery capacity is influenced by the dynamic behaviour depending on transient phases of driving cycle (power source). The FC dynamics are sett using different time responses. The results maps are obtained considering the system's parameters in Table 1.

Table 1. Methodology and vehicle parameters.

\begin{tabular}{cccc}
\hline Parameter & Value & Parameter & Value \\
\hline Particles number and Iteration & 30,100 & Vehicle mass $(\mathrm{kg})$ & 1428 \\
Values to design & $P_{F C}, C_{B A T}$ & Air density $\left(\mathrm{kg} \cdot \mathrm{m}^{-3}\right)$ & 1.2 \\
Search field: $P_{F C}, C_{B A T}$ & $1-50 \mathrm{~kW}$ and $1-10 \mathrm{kWh}$ & Friction coefficient & 0.012 \\
Fuel cell, battery models & PEMFC static, Li-Ion model & Aerodynamic coefficient & 0.29 \\
$S O C_{\text {Min }}, S O C_{\text {Max }}$ & $15 \%, 90 \%$ & Front surface area $\left(\mathrm{m}^{2}\right)$ & 2.69 \\
$\gamma, \alpha, \beta$ & $1400,-20,1700$ & $\delta, \rho, \sigma$ & $125,-1600,4400$ \\
\hline
\end{tabular}

Figure 10 presents sizing solutions considering the reliability effect under WLTC and US highway using the same fuel cell dynamic (10 s). The aim is to see how the developed approach considers the variation of operating conditions (sensitivity of the approach). Overall, the design approach makes an appropriate sizing; the FC is very closely to the system autonomy by ensuring the load average. Conversely, battery capacity attends dynamic behaviour given by the energy deviation. This deviation impacts the battery thermal behaviour (cycling effect), which is directly calculated using the mathematical model presented previously and correlated to the dynamic driving cycle. The WLTC 
driving power presents many transitory phases (numerous and intense) implying a significant impact on battery lifetime (deep cycling). On the contrary, the US highway certification cycle has less impact on the battery lifetime because of a lower dynamic range (driving mode). Technically, the standard deviation of the battery exchanged energy is significantly different between the WLTC cycle and the US highway one: $1.2 \mathrm{kWh}$ and $0.36 \mathrm{kWh}$, respectively. Similarly this trend is reflected in the value of the lifetime loss which is in roughly three times larger in the WLTC mapping (Figure 10b,d), for example, for sizing architecture $\left(\mathrm{P}_{\mathrm{FC}}=20 \mathrm{KW}, C_{\text {Batt }}=3 \mathrm{KWh}\right)$, the lifetime losses are: $0.01 \%$ for US highway and $0.032 \%$ for WLTC.

(a) Batt Lifetime Mapping US Highway for 10s

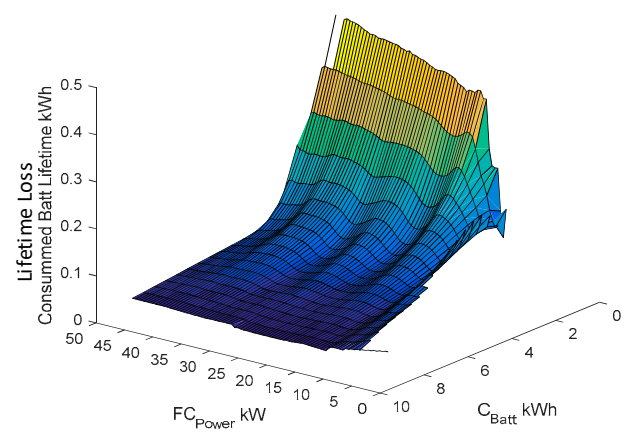

(c) Batt Lifetime Mapping WLTC for 10 s

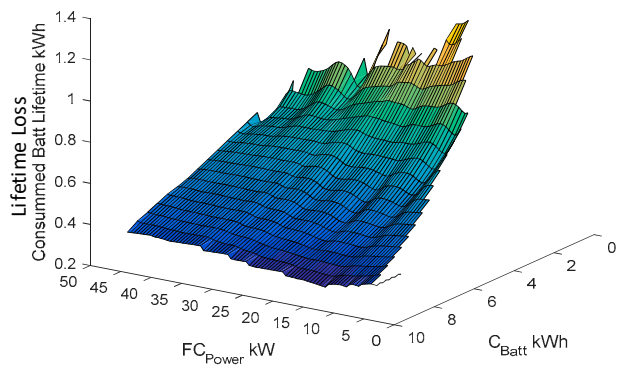

(b) Batt Lifetime Mapping US Highway for 10s

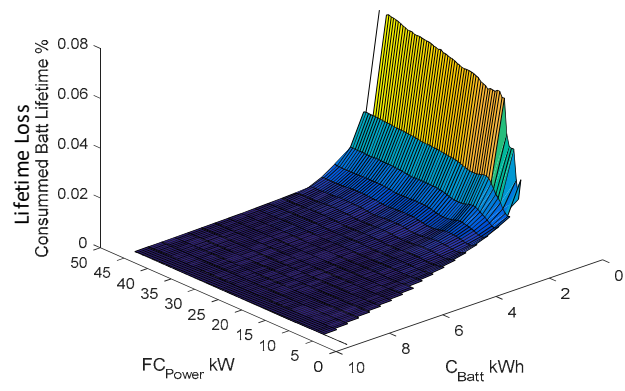

(d) Batt Lifetime Mapping WLTC for 10s

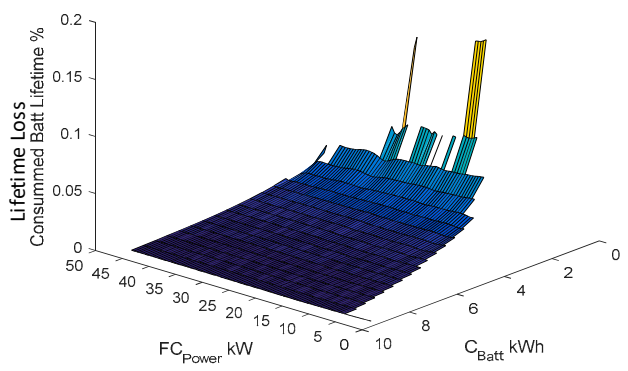

Figure 10. Design results considering lifetime loss (KW/h or \%) according to US Highway and WLTC driving cycle. (a) Result mapping with battery lifetime loss (KW/h), US Highway and FC dynamic 10 s. (b) Result mapping with battery lifetime loss (\%), US Highway and FC dynamic 10 s. (c) Result mapping with battery lifetime loss (KW/h), WLTC and FC dynamic $10 \mathrm{~s}$. (d) Result mapping with battery lifetime loss (\%), WLTC and FC dynamic $10 \mathrm{~s}$.

In order to introduce more flexibility about hybridization rate, three different FC response times $(1 \mathrm{~s}, 5 \mathrm{~s}, 10 \mathrm{~s})$ are considered while using the same certification driving cycle (namely US 06) as illustrated in Figure 11. The surface shape of this sizing solution is slightly influenced by the FC dynamics. The lifetime loss remains relatively low according to the battery dynamic behaviour Figure $11 \mathrm{~b}, \mathrm{~d}$, $\mathrm{f}$, indicating that the design approach makes the best trade-off towards this requirement. For example, for sizing architecture $\left(P_{F C}=20 \mathrm{KW}, C_{\text {Batt }}=3 \mathrm{KWh}\right)$, the life time losses are: $0.009 \%$ for FC dynamic $1 \mathrm{~s}, 0.01 \%$ for FC dynamic $5 \mathrm{~s}$ and $0.0115 \%$ for FC dynamic $10 \mathrm{~s}$.

In sum, for the optimal zone, the results show that, to meet reliability constraints, the designer applies a slight oversizing of the battery compared to the energy constraint solution. This behaviour is proved by the global ramp of the mapping, which decreases, with the increase of the battery capacity. In addition, the sizing of the FC also influences the battery reliability with a bowl effect in accordance with the optimal FC power value. These results show the antagonistic behaviour of the reliability objective towards the energy saving one.

These different effects show that the key challenge is to simultaneously take into account several objectives in a global design approach. Indeed, the fuel consumption criterion tends to decrease the 
battery sizing in order to limit the embedded mass while the reliability criterion leads to increase this sizing so as to enhance the power capability, thus reducing the battery degradation and its lifetime loss. These results of this approach enables to decide between several proposed sizes.

(a) Batt Lifetime Mapping US 06 for 1s

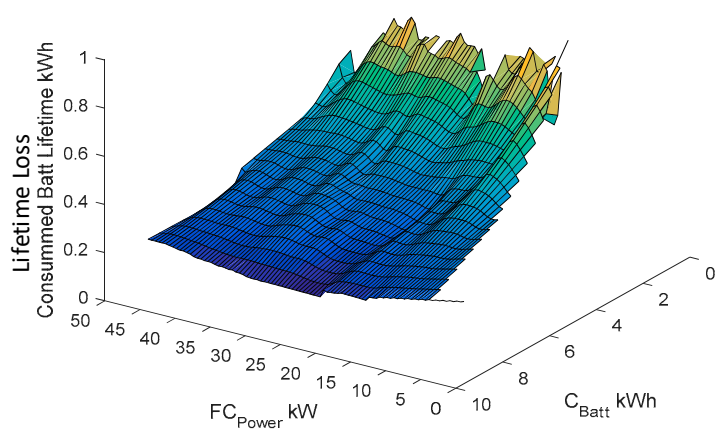

(c) Batt Lifetime Mapping US 06 for $5 \mathrm{~s}$

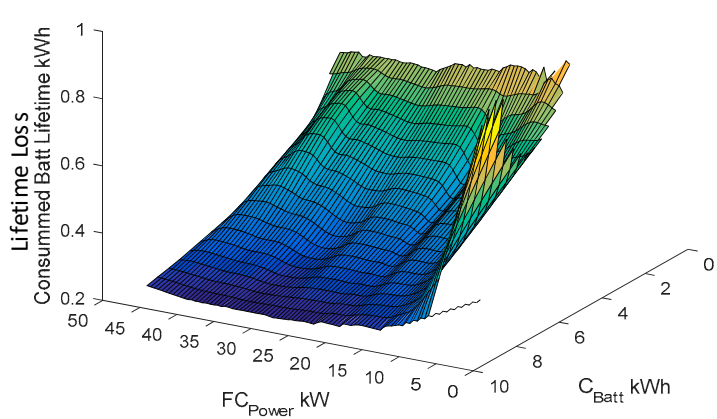

(e) Batt Lifetime Mapping US 06 for 10 s

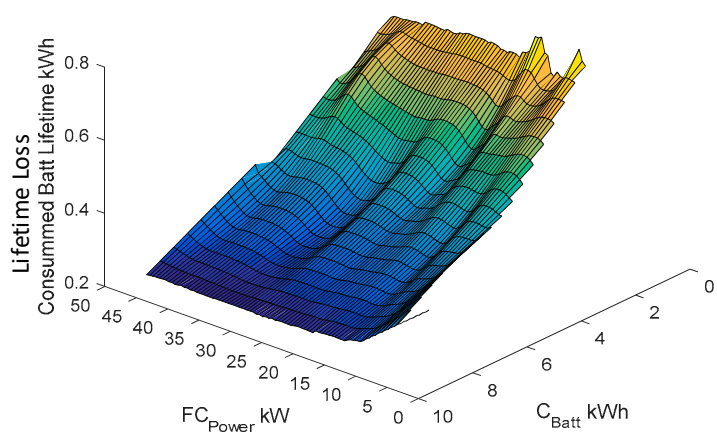

(b) Batt Lifetime Mapping US 06 for $1 \mathrm{~s}$

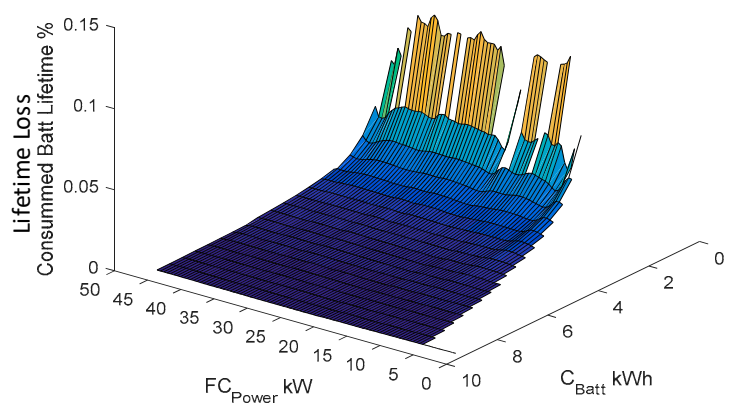

(d) Batt Lifetime Mapping us 06 for $5 \mathrm{~s}$

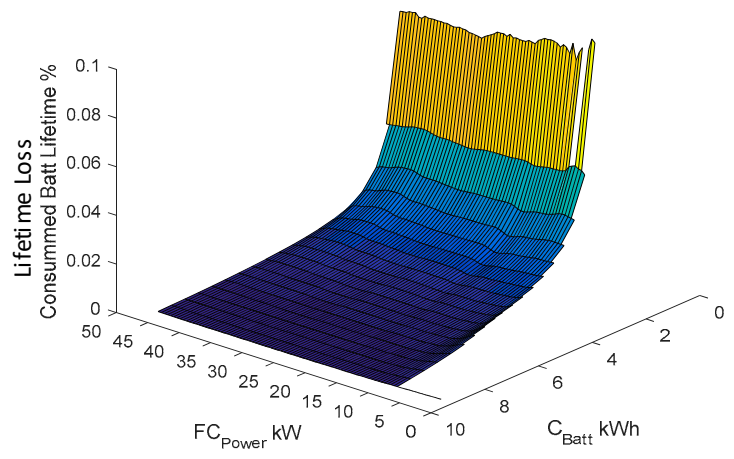

(f) Batt Lifetime Mapping US 06 for 10s

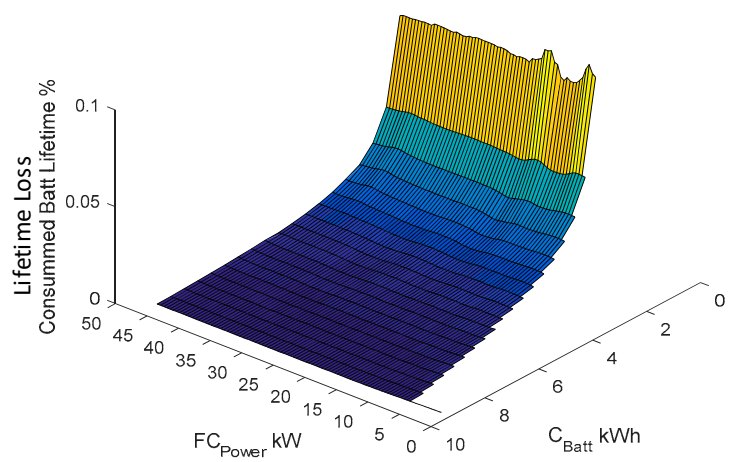

Figure 11. Design results (fuel cell power $\mathrm{FC}_{\text {power }}$ and battery capacity $C_{\text {Batt }}$ ) considering lifetime loss (KW/h or \%)-US 06 driving cycle under different FC dynamics (1 s, $5 \mathrm{~s}$ and $10 \mathrm{~s}$ ). (a) Result mapping with battery lifetime loss (KW/h) and FC dynamic $1 \mathrm{~s}$. (b) Result mapping with battery lifetime loss (\%) and FC dynamic $1 \mathrm{~s}$. (c) Result mapping with battery lifetime loss (KW/h) and FC dynamic $5 \mathrm{~s}$. (d) Result mapping with battery lifetime loss (\%) and FC dynamic 5 s. (e) Result mapping with battery lifetime loss (KW/h) and FC dynamic $10 \mathrm{~s}$. (f) Result mapping with battery lifetime loss (\%) and FC dynamic $10 \mathrm{~s}$.

To evaluate the representativeness of the obtained results, time simulation tests of the proposed powertrain are carried out using a standard WLTC drive cycle. With a distance of $23 \mathrm{~km}$, the WLTC provides a specific consumption around $0.72 \mathrm{~kg} / 100 \mathrm{~km}$, considering the optimized architecture 
illustrated in Table 2. This performance is highly encouraging, since it is very close to the standard driving cycle of electric vehicles, which proves the relevance of suggested approach.

Table 2. Optimization results-WLTC.

\begin{tabular}{cc}
\hline Variable & Value \\
\hline Fuel cell power & $30 \mathrm{~kW}$ \\
Battery power & $19.5 \mathrm{~kW}$ \\
Battery capacity & $6.5 \mathrm{kWh}$ \\
Hydrogen consumption & $0.72 \mathrm{~kg} / 100 \mathrm{~km}$ \\
Computation Time & $900 \mathrm{~s}$ \\
Battery lifetime-Number of cycles WLTC & 10,000 \\
Battery lifetime-Total exchanged energy & $4500 \mathrm{kWh}$ \\
\hline
\end{tabular}

Figure 12 presents the optimal fuel cell/battery system response with the key variable waveforms: the load power $\left(\mathrm{P}_{\text {Load }}\right)$, the relative FC power, the state of charge (SOC) and the FC efficiency. Obviously, the FC is requested between $15 \%$ and $50 \%$ of its rated power, which belongs to the best range of FC energy efficiency, thanks to the energetic strategy, which makes use of the FC in its best range.
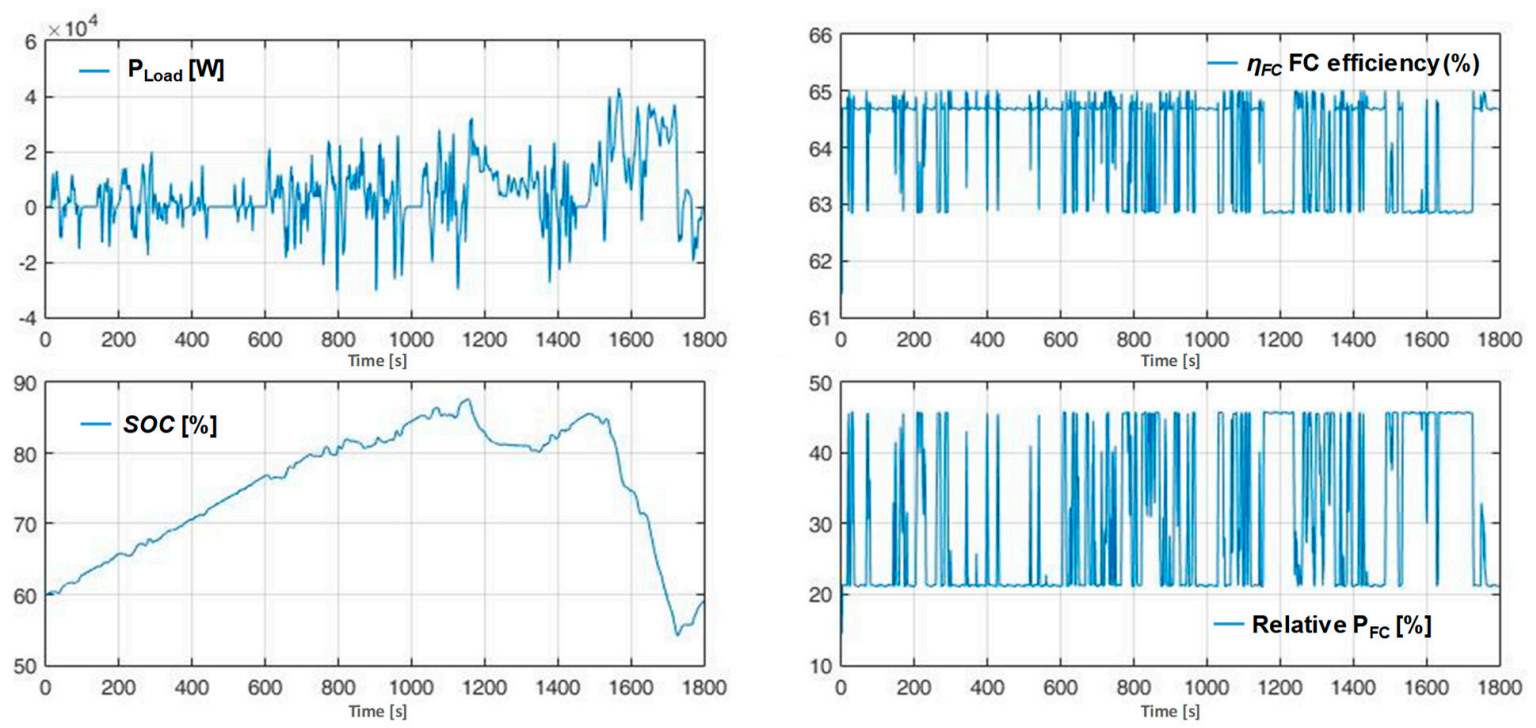

Figure 12. Testing of the optimized system on the WLTC standard cycle.

The SOC trajectory tends to follow the vehicle dynamic behaviour and reaches the required final condition. This demonstrates the effectiveness of the dichotomy technique for finding the proper co-state tuning value

\section{Conclusions}

To be more suited to industrial challenges, the current study addresses the reliability process integration into the design approach based on an energetic performance index.

The proposed approach considers a linear trend extrapolation of battery $\mathrm{SOH}$ based on data test analyses, in order to avoid the limits of conventional approaches: complexity, expensive and time-consuming implementation. It produces very fast results with sufficient accuracy suitable for the optimization sizing approach. This makes it possible to consider different driving cycles and operating conditions.

The results show a correlation between energy constraint and reliability impact. Battery lifetime loss is influenced by the dynamic range, dependent on the driving cycle. Therefore, to meet the reliability constraint, the designer applies a battery oversizing compared to a solution limited to a 
single energy constraint. However, the results reflect a global trend; it should be considered in a relative way and not in an absolute one which represents the main limit of the present approach.

This work shows the relevance of a multi-objective approach in a design process because of the growing complexity of considering several conflicting or non-conflicting objectives.

Based on this approach, future work will consider including the reliability effect at the same level as the energy one. This multi-objective optimization will permit a simultaneous approach and enable making the best trade-offs with respect to the specifications.

Author Contributions: Conceptualization, A.C., T.A., O.B. and F.A.; methodology, A.C. and T.A.; formal analysis, T.A. and O.B.; writing-original draft preparation, A.C. and T.A.; writing-review and editing, T.A., O.B. and F.A.; supervision, O.B. and F.A., All authors have read and agreed to the published version of the manuscript.

Funding: This research received no external funding.

Conflicts of Interest: The authors declare no conflict of interest.

\section{Abbreviations}

\begin{tabular}{|c|c|}
\hline $\mathrm{HEV}$ & Hybrid Electric Vehicle \\
\hline PSO & Particle Swarm Optimization \\
\hline PMP & Pontryagin's Minimum Principle \\
\hline EV & Electrical Vehicle \\
\hline $\mathrm{FCHV}$ & Fuel Cell Hybrid Vehicle \\
\hline PEMFC & Proton Exchange Membrane Fuel Cell \\
\hline $\mathrm{SOH}$ & State Of Health \\
\hline WLTC & Worldwide Harmonized Light Vehicles Test Cycles \\
\hline US Highway & Highway United States Test Cycle \\
\hline US06 & Supplemental United States Test Cycle \\
\hline VPD & Vector of Power Distribution \\
\hline WV & Weighting Vector \\
\hline $\mathrm{D}$ & Degradation degree \\
\hline $\mathrm{L}_{\text {Loss }}$ & Lifetime loss \\
\hline SOE & State of Energy \\
\hline DOD & Depth of Discharge \\
\hline $\mathrm{CCCV}$ & Constant Current Constant Voltage \\
\hline $\mathrm{CC}$ & Constant Current \\
\hline EOL & End-of-Life \\
\hline$P_{F C / M a x / M i n}$ & Fuel cell power, Maximum, Minimum, (W) \\
\hline$P_{B A T / M a x / M i n}$ & Battery power, Maximum, Minimum, (W) \\
\hline$C_{B A T / M a x / M i n}$ & Battery capacity, Maximum, Minimum, (Ah) \\
\hline$S O C_{B A T / M a x / M i n}$ & Battery state of charge, Maximum, Minimum, (\%) \\
\hline$\eta_{F C} \eta_{B A T}$ & Fuel cell and Battery efficiency, (\%) \\
\hline$H$ & Hamiltonian function \\
\hline$\lambda$ & Co-state, Lagrange multiplier \\
\hline$P_{\text {Dem }}$ & Power demand, $(\mathrm{W})$ \\
\hline$C_{r}, C_{x}$ & Friction and aerodynamic coefficients \\
\hline$\rho$ & Air density, $\left(\mathrm{kg} \cdot \mathrm{m}^{-3}\right)$ \\
\hline$S$ & Front surface area, $\left(\mathrm{m}^{2}\right)$ \\
\hline M & Vehicle mass, $(\mathrm{kg})$ \\
\hline$g$ & Gravity acceleration, $\left(\mathrm{m} . \mathrm{s}^{-2}\right)$ \\
\hline$\alpha$ & Slope of the road, (deg) \\
\hline$C_{B A T, C}, C_{B A T, I n i t}$ & Current and initial battery capacity, (Wh) \\
\hline$S O C, S O C_{0}$ & Current and initial State Of Charge, $(\%)$ \\
\hline$i_{B A T}$ & Battery current, (A) \\
\hline$S O H_{D O D}$ & State of health as a function of DOD \\
\hline $\mathrm{SOH}_{I c}$ & State of health as a function of rated current. \\
\hline$N_{C y c l e, D O D}$ & Number of cycles according to a DOD level \\
\hline$N_{\text {Cycle,Ic }}$ & Number of cycles according to a ratted current. \\
\hline$C_{\text {rate }}$ is & Charging/discharge current, (A) \\
\hline$\alpha, \beta, \gamma, \delta, \rho, \sigma$ & Fitting parameters. \\
\hline$E_{B A T}$ & Battery cumulated energy, (J or Wh) \\
\hline$E_{B A T, T o t, \text { Init }}, N_{C y c l e, \text { Init }}$ & Total initial battery energy and number of cycle. \\
\hline$T_{S}$ & Simple time, $(\mathrm{s})$ \\
\hline
\end{tabular}




\section{References}

1. Muneer, T.; Kolhe, M.; Doyle, A. Electric Vehicles: Prospects and Challenges; Elsevier: New York, NY, USA, 2017; ISBN 978-0-12-803021-9.

2. Kaya, K.; Hames, Y. Two new control strategies: For hydrogen fuel saving and extend the life cycle in the hydrogen fuel cell vehicles. Int. J. Hydrog. Energy 2019, 44, 18967-18980. [CrossRef]

3. Yue, M.; Jemei, S.; Gouriveau, R.; Zerhouni, N. Review on health-conscious energy management strategies for fuel cell hybrid electric vehicles: Degradation models and strategies. Int. J. Hydrog. Energy 2019, 44, 6844-6861. [CrossRef]

4. Yao, G.; Du, C.; Ge, Q.; Jiang, H.; Wang, Y.; Ait-Ahmed, M.; Moreau, L. Traffic-Condition-Prediction-Based HMA-FIS Energy-Management Strategy for Fuel-Cell Electric Vehicles. Energies 2019, 12, 4426. [CrossRef]

5. Fu, Z.; Li, Z.; Si, P.; Tao, F. A hierarchical energy management strategy for fuel cell/battery/supercapacitor hybrid electric vehicles. Int. J. Hydrog. Energy 2019, 44, 22146-22159. [CrossRef]

6. Egan, P.; Cagan, J. Human and Computational Approaches for Design Problem-Solving. In Experimental Design Research; Cash, P., Stanković, T., Štorga, M., Eds.; Springer International Publishing: Cham, Switzerland, 2016; pp. 187-205. ISBN 978-3-319-33779-1.

7. Serpi, A.; Porru, M. Modelling and Design of Real-Time Energy Management Systems for Fuel Cell/Battery Electric Vehicles. Energies 2019, 12, 4260. [CrossRef]

8. Silvas, E.; Hofman, T.; Murgovski, N.; Etman, L.F.P.; Steinbuch, M. Review of Optimization Strategies for System-Level Design in Hybrid Electric Vehicles. IEEE Trans. Veh. Technol. 2017, 66, 57-70. [CrossRef]

9. Yang, Y.; Shang, Z.; Chen, Y.; Chen, Y. Multi-Objective Particle Swarm Optimization Algorithm for Multi-Step Electric Load Forecasting. Energies 2020, 13, 532. [CrossRef]

10. Hu, X.; Martinez, C.M.; Egardt, B.; Cao, D. Multi-objective optimal sizing and control of fuel cell systems for hybrid vehicle applications. In Proceedings of the 2015 European Control Conference (ECC), Linz, Austria, 15-17 July 2015; pp. 2559-2564.

11. Zhou, X.; Qin, D.; Hu, J. Multi-objective optimization design and performance evaluation for plug-in hybrid electric vehicle powertrains. Appl. Energy 2017, 208, 1608-1625. [CrossRef]

12. Nandi, A.K.; Chakraborty, D.; Vaz, W. Design of a comfortable optimal driving strategy for electric vehicles using multi-objective optimization. J. Power Sources 2015, 283, 1-18. [CrossRef]

13. Gharibi, M.; Askarzadeh, A. Size and power exchange optimization of a grid-connected diesel generator-photovoltaic-fuel cell hybrid energy system considering reliability, cost and renewability. Int. J. Hydrog. Energy 2019, 44, 25428-25441. [CrossRef]

14. Chen, H.; Yang, C.; Deng, K.; Zhou, N.; Wu, H. Multi-objective optimization of the hybrid wind/solar/fuel cell distributed generation system using Hammersley Sequence Sampling. Int. J. Hydrog. Energy 2017, 42, 7836-7846. [CrossRef]

15. Faddel, S.; Elsayed, A.T.; Mohammed, O.A. Bilayer Multi-Objective Optimal Allocation and Sizing of Electric Vehicle Parking Garage. IEEE Trans. Ind. Appl. 2018, 54, 1992-2001. [CrossRef]

16. Song, X.; Lin, H.; De, G.; Li, H.; Fu, X.; Tan, Z. An Energy Optimal Dispatching Model of an Integrated Energy System Based on Uncertain Bilevel Programming. Energies 2020, 13, 477. [CrossRef]

17. Ceschia, A.; Azib, T.; Bethoux, O.; Alves, F. Sensitivity Analysis of an Optimal Design Methodology for Hybrid Power System. In Proceedings of the 2019 6th International Conference on Control, Decision and Information Technologies (CoDIT), Paris, France, 23-26 April 2019; pp. 1277-1282.

18. Tran, D.-D.; Vafaeipour, M.; El Baghdadi, M.; Barrero, R.; Van Mierlo, J.; Hegazy, O. Thorough state-of-the-art analysis of electric and hybrid vehicle powertrains: Topologies and integrated energy management strategies. Renew. Sustain. Energy Rev. 2020, 119, 109596. [CrossRef]

19. Biegler, L.T. An overview of simultaneous strategies for dynamic optimization. Chem. Eng. Process. Process Intensif. 2007, 46, 1043-1053. [CrossRef]

20. Herber, D.R.; Allison, J.T. Nested and Simultaneous Solution Strategies for General Combined Plant and Control Design Problems. J. Mech. Des. 2019, 141, 11402-11413. [CrossRef]

21. Chen, Z.; Xiong, R.; Wang, K.; Jiao, B. Optimal Energy Management Strategy of a Plug-in Hybrid Electric Vehicle Based on a Particle Swarm Optimization Algorithm. Energies 2015, 8, 3661-3678. [CrossRef]

22. Yang, R.; Yuan, Y.; Ying, R.; Shen, B.; Long, T. A Novel Energy Management Strategy for a Ship's Hybrid Solar Energy Generation System Using a Particle Swarm Optimization Algorithm. Energies 2020, 13, 1380. [CrossRef] 
23. Yuan, Z.; Teng, L.; Fengchun, S.; Peng, H. Comparative Study of Dynamic Programming and Pontryagin's Minimum Principle on Energy Management for a Parallel Hybrid Electric Vehicle. Energies 2013, 6, $2305-2318$. [CrossRef]

24. Liu, J.; Feng, L.; Li, Z. The Optimal Road Grade Design for Minimizing Ground Vehicle Energy Consumption. Energies 2017, 10, 700. [CrossRef]

25. Liu, C.; Liu, L. Optimal power source sizing of fuel cell hybrid vehicles based on Pontryagin's minimum principle. Int. J. Hydrog. Energy 2015, 40, 8454-8464. [CrossRef]

26. Wang, Y.; Moura, S.J.; Advani, S.G.; Prasad, A.K. Optimization of powerplant component size on board a fuel cell/battery hybrid bus for fuel economy and system durability. Int. J. Hydrog. Energy 2019, 44, 18283-18292. [CrossRef]

27. Song, Z.; Zhang, X.; Li, J.; Hofmann, H.; Ouyang, M.; Du, J. Component sizing optimization of plug-in hybrid electric vehicles with the hybrid energy storage system. Energy 2018, 144, 393-403. [CrossRef]

28. Moura, S.J.; Stein, J.L.; Fathy, H.K. Battery-Health Conscious Power Management in Plug-In Hybrid Electric Vehicles via Electrochemical Modeling and Stochastic Control. IEEE Trans. Control Syst. Technol. 2013, 21, 679-694. [CrossRef]

29. Maghami, M.R.; Hassani, R.; Gomes, C.; Hizam, H.; Othman, M.L.; Behmanesh, M. Hybrid energy management with respect to a hydrogen energy system and demand response. Int. J. Hydrog. Energy 2020, 45, 1499-1509. [CrossRef]

30. Li, H.; Ravey, A.; N'Diaye, A.; Djerdir, A. A novel equivalent consumption minimization strategy for hybrid electric vehicle powered by fuel cell, battery and supercapacitor. J. Power Sources 2018, 395, 262-270. [CrossRef]

31. Benmouna, A.; Becherif, M.; Chen, J.; Chen, H.; Depernet, D. Interconnection and damping assignment passivity based control for fuel cell and battery vehicle: Simulation and experimentation. Int. J. Hydrog. Energy 2019, 44, 22467-22477. [CrossRef]

32. Tao, L.; Ma, J.; Cheng, Y.; Noktehdan, A.; Chong, J.; Lu, C. A review of stochastic battery models and health management. Renew. Sustain. Energy Rev. 2017, 80, 716-732. [CrossRef]

33. Martinez-Laserna, E.; Gandiaga, I.; Sarasketa-Zabala, E.; Badeda, J.; Stroe, D.-I.; Swierczynski, M.; Goikoetxea, A. Battery second life: Hype, hope or reality? A critical review of the state of the art. Renew. Sustain. Energy Rev. 2018, 93, 701-718. [CrossRef]

34. Azib, T.; Bethoux, O.; Remy, G.; Marchand, C.; Berthelot, E. An Innovative Control Strategy of a Single Converter for Hybrid Fuel Cell/Supercapacitor Power Source. IEEE Trans. Ind. Electron. 2010, 57, 4024-4031. [CrossRef]

35. Wilberforce, T.; Khatib, F.N.; Ijaodola, O.S.; Ogungbemi, E.; El-Hassan, Z.; Durrant, A.; Thompson, J.; Olabi, A.G. Numerical modelling and CFD simulation of a polymer electrolyte membrane (PEM) fuel cell flow channel using an open pore cellular foam material. Sci. Total Environ. 2019, 678, 728-740. [CrossRef] [PubMed]

36. Thompson, A.W. Economic implications of lithium ion battery degradation for Vehicle-to-Grid (V2X) services. J. Power Sources 2018, 396, 691-709. [CrossRef]

37. Babin, A.; Rizoug, N.; Mesbahi, T.; Boscher, D.; Hamdoun, Z.; Larouci, C. Total Cost of Ownership Improvement of Commercial Electric Vehicles Using Battery Sizing and Intelligent Charge Method. IEEE Trans. Ind. Appl. 2018, 54, 1691-1700. [CrossRef]

38. Maher, K.; Yazami, R. A study of lithium ion batteries cycle aging by thermodynamics techniques. J. Power Sources 2014, 247, 527-533. [CrossRef]

39. Maheshwari, A.; Heck, M.; Santarelli, M. Cycle aging studies of lithium nickel manganese cobalt oxide-based batteries using electrochemical impedance spectroscopy. Electrochim. Acta 2018, 273, 335-348. [CrossRef]

40. Tang, X.; Zou, C.; Yao, K.; Chen, G.; Liu, B.; He, Z.; Gao, F. A fast estimation algorithm for lithium-ion battery state of health. J. Power Sources 2018, 396, 453-458. [CrossRef]

41. Ma, S.; Jiang, M.; Tao, P.; Song, C.; Wu, J.; Wang, J.; Deng, T.; Shang, W. Temperature effect and thermal impact in lithium-ion batteries: A review. Prog. Nat. Sci. Mater. Int. 2018, 28, 653-666. [CrossRef]

42. Pelletier, S.; Jabali, O.; Laporte, G.; Veneroni, M. Battery degradation and behaviour for electric vehicles: Review and numerical analyses of several models. Transp. Res. Part B Methodol. 2017, 103, 158-187. [CrossRef]

43. Han, X.; Ouyang, M.; Lu, L.; Li, J. A comparative study of commercial lithium ion battery cycle life in electric vehicle: Capacity loss estimation. J. Power Sources 2014, 268, 658-669. [CrossRef] 
44. Martel, F.; Dubé, Y.; Kelouwani, S.; Jaguemont, J.; Agbossou, K. Long-term assessment of economic plug-in hybrid electric vehicle battery lifetime degradation management through near optimal fuel cell load sharing. J. Power Sources 2016, 318, 270-282. [CrossRef]

45. Leng, F.; Tan, C.M.; Pecht, M. Effect of Temperature on the Aging rate of Li Ion Battery Operating above Room Temperature. Sci. Rep. 2015, 5, 12967. [CrossRef] [PubMed]

46. Zou, Y.; Hu, X.; Ma, H.; Li, S.E. Combined State of Charge and State of Health estimation over lithium-ion battery cell cycle lifespan for electric vehicles. J. Power Sources 2015, 273, 793-803. [CrossRef]

47. Ecker, M.; Nieto, N.; Käbitz, S.; Schmalstieg, J.; Blanke, H.; Warnecke, A.; Sauer, D.U. Calendar and cycle life study of Li(NiMnCo)O2-based 18650 lithium-ion batteries. J. Power Sources 2014, 248, 839-851. [CrossRef]

48. Quinard, H.; Redondo-Iglesias, E.; Pelissier, S.; Venet, P. Fast Electrical Characterizations of High-Energy Second Life Lithium-Ion Batteries for Embedded and Stationary Applications. Batteries 2019, 5, 33. [CrossRef]

49. Martel, F.; Kelouwani, S.; Dubé, Y.; Agbossou, K. Optimal economy-based battery degradation management dynamics for fuel-cell plug-in hybrid electric vehicles. J. Power Sources 2015, 274, 367-381. [CrossRef]

(C) 2020 by the authors. Licensee MDPI, Basel, Switzerland. This article is an open access article distributed under the terms and conditions of the Creative Commons Attribution (CC BY) license (http://creativecommons.org/licenses/by/4.0/). 